\section{QIJEI}

\author{
International \\ Journal for \\ Educational \\ Integrity
}

\title{
Editorial Volume 6 (1)
}

I am pleased to introduce the next issue of the International Journal for Educational Integrity. This issue includes revised papers from two key conferences in 2009: the $4^{\text {th }}$ Asia Pacific Conference on Educational Integrity (4APCEI, Wollongong University, Australia), and the Center for Academic Integrity Annual International Conference (Washington University, US), as well as two original papers. The issue is truly international, with authors representing the United States, the Ukraine and Australia.

Daniel Wueste, Director of the Rutland Institute for Ethics, and Teddi Fishman, Director of the recently renamed International Center for Academic Integrity, provide a framing piece for the issue, with their paper from 4APCEI which explores the limitations of customer service approaches in higher education. Wueste and Fishman, while acknowledging the seductive appeal of likening students to "customers", particularly as part of the "total quality movement", provide a rigorous critique of this potentially dangerous discourse. The authors demonstrate how education differs quite significantly from commerce and argue that "looking to professional practice for help in understanding the educational enterprise holds considerably more promise than looking to business practice". Wueste and Fishman are forthright in their assertion that education is based on a reciprocal relationship between teacher and learner (rather than a transaction between vendor and vendee), and that intrinsic to this relationship is a shared commitment to integrity.

Following on from Wueste's and Fishman's call for a re-articulation of values in higher education, are two papers from the CAI conference. Joanna Gilmore, Denise Strickland, Briana Timmerman, Michelle Maher (all from the University of South Carolina) and David Feldon (University of Virginia), investigate plagiarism by graduate students. Working with a sample of 113 masters and doctoral students from three university sites, representing technology, engineering, mathematics, or mathematics or science education, the researchers examined students' research proposals and conducted semi-structured interviews. Their key finding was that while plagiarism was a prevalent issue (almost $40 \%$ of the proposals contained notable plagiarism), this appeared to be largely unintentional due to a lack of disciplinary enculturation. Notably, this lack of disciplinary enculturation was further compounded for English as a Second Language (ESL) students at the pre-proposal stage, who also had to grapple with cultural differences, English language issues and a variety of other factors.

William Hanson from Anderson University in California uses grounded theory and graph theory based analysis to create a "faculty ethics logic model" based on his research at a small, religiously affiliated university. Hanson sought to operationalise participant realities of the primary forces that drive teaching or resolving ethics issues and discovered that informal elements, rather than formal institutional influence, played a major role in response strategies. In particular, faculty members used existing knowledge, resources/artefacts, goals and beliefs and their actions were shaped by work group influence and collective norms within a Christian framework. Hanson concluded that ethics policy "cannot be wholly forced upon its members... informal institutional principles originate from faculty" and that teachers "must be considered as primary change agents in ethics reform..." This research has important implications in the context of academic integrity, pointing as it does to the

The International Journal for Educational Integrity is available online at:

http://www.ojs.unisa.edu.au/journals/index.php/IJEl/

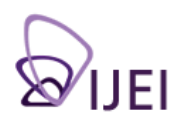


central, although often informal role of teachers in nurturing and promoting academic integrity on campus.

Jason Stephens (University of Connecticut), Volodymyr Romakin (Petro Mohyla State University, Ukraine) and Mariya Yukhymenko (University of Connecticut) extend previous studies which have compared cheating behaviours of US undergraduate students with students from other cultures, by investigating academic motivation and misconduct by Ukrainian students. Based on a self-report survey with a sample of 189 students from each country, their study investigated the differences between US and Ukrainian students' task value, goal orientations, moral beliefs and cheating behaviours. Significant differences between the two groups were found, most notably that Ukrainian students reported lower judgements about the wrongfulness of cheating behaviours, and correspondingly higher levels of engagement in cheating behaviour. In particular, academic task value was a significant predictor of cheating beliefs and behaviours for the Ukrainian students: the more useful and interesting the course was perceived to be, the less likely the Ukrainian students were to cheat - a finding which has clear implications for all educators, but particularly those working with Ukrainian students.

The final paper by Australian authors, Robert Kennelly, Anna Maldoni and Doug Davis (University of Canberra) provides appropriate closure to this issue. While Wueste and Fishman opened the issue by exhorting us to re-examine the value and purpose of higher education, Kennelly et al. do just that by reminding readers that educational integrity requires more than a pledge from students not to cheat. All stakeholders, from those at the highest administrative level, to those instructors teaching occasional tutorials, need to be deeply committed to the learning needs of the diverse classroom. International EAL (English as an Additional Language) students in Australian universities have long carried the burden associated with the customer service model of higher education critiqued by Wueste and Fishman. International EAL students pay high tuition fees, have additional expenses and responsibilities to fulfil English language requirements (in most Australian universities, a minimum International English Language Test Score (IELTS) of 6.00 for undergraduate entry), and in many instances, find at arrival that this IELTS score is inadequate for the level of oral and written communication required. Furthermore, with decreasing government funding and the demise of student unions, the level of on-campus services has gradually declined, so that students not only struggle with their academic load, they are often lonely and isolated. The discipline-based approach to academic and language development trialled, evaluated and recommended by Kennelly et al. goes some way to addressing the academic needs of this group of students. Using data from six consecutive semesters, the authors provide compelling evidence that team-taught, disciplined-based support programs have the potential to improve international EAL students' competence in academic and critical literacy skills, while simultaneously building English language proficiency.

I trust you will enjoy this issue of the International Journal for Educational Integrity, and invite you to submit manuscripts for review for Volume 7(1), to be published in mid-2011. Volume 6(2) is being guest edited by Chris Moore and Ruth Walker, on the topic of 'digital technologies and educational integrity' and is due to be published in December this year.

Tracey Bretag, IJEl Editor

tracey.bretag@unisa.edu.au 